\title{
Investigation of the Relationship between Informal Relations and Employee Creativity in Media Companies
}

\author{
Shoja Parham ${ }^{1}$, Reza Zadeh Mohammad ${ }^{2}$ \\ ${ }^{1}$ shojaparham@yahoo.com \\ 2 mohammadr766@gmail.com
}

\begin{tabular}{|c|c|}
\hline ARTICLE INFO & ABSTRACT \\
\hline $\begin{array}{l}\text { Keywords: } \\
\text { Informal Relations } \\
\text { Creativity } \\
\text { Media Companies }\end{array}$ & $\begin{array}{l}\text { The present study investigates the relationship between the } \\
\text { employees' informal relations and their creativity. This research was } \\
\text { conducted to recognize the informal relations of employees as one } \\
\text { of the ways to enhance creativity in an organization. Data was } \\
\text { gathered using the quantitative method and the questionnaire } \\
\text { technique based on the human relations approach. Also, all } \\
\text { employees of Media companies at Tehran were considered as the } \\
\text { statistical population and } 50 \text { were examined as the samples of the } \\
\text { study. After data analysis, the findings indicated that there was no } \\
\text { relationship between creativity and informal relations, and informal } \\
\text { relations cannot directly be considered to boost creativity. }\end{array}$ \\
\hline
\end{tabular}

\section{Introduction}

By considering the collection of human cultural achievements in arts, literature, philosophy, and equipment that make up the human life in the twentieth century, it is seen that even the simplest available things in this collection (such as desks, chairs and so on) are also the product of a thinker's and inventor's creativity and innovation, which have come to their current form over years by processing ideas, theories and emergence of innovation (Rezaian, 2008).

All organizations need new thoughts and ideas for survival. New thoughts and ideas are blown like a soul into the body of the organization, and they save it from a breakdown in the organization (Alvani, 2010). The growth and development of creativity are dependent on various personal and social factors, such as intelligence, family, personality traits, etc. Although the ability of creativity is potential and innate in human beings, the emergence of it requires appropriate education (Mami and Amirian, 2016).

Two words of opportunities and external threats are the key terms in strategic management. External opportunities and threats are events and economic, social, cultural, ecological, environmental, political, legal, state, technology, and competitive trends that can greatly make loss and gain for the organization in the future. Opportunities and threats are largely out of the control of an organization, hence the word external is used (David, 2016).

Informal networks and systems created by the interaction of people are examples of threats that if they conflict with the goals of the organization, they will interfere with the achievement of the goals of the organization. But, with a broader view, this type of communication has served as a proper ground to flow creative ideas and enhance the creativity among employees and this threat can be used as an appropriate opportunity to boost creativity in the organization.

One of the goals of a scientific research is to describe the nature of a population that is a group, a group of people under investigation, variables, concepts, or phenomena (Wimmer and Dominick, 2014). This research also aims to investigate the level of informal relations among individuals and their creativity in media companies and provide a solution to enhance creativity in the organization if there is a relationship between these two variables. 


\section{Communication}

The word communication used in communication science involves various concepts, such as the transmission and diffusion of awareness and ideas, creating social cohesion, mindshare (mind participation), and public co-operation (Motamednejad, 2012).

Aristotle, the Greek philosopher, is perhaps the first thinker who first talked about the communication 2300 years ago. In the book of Rhetoric, commonly referred to as the synonym of communication, he defines the communication as the ability to find all available means of persuasion (Mohsenian Rad, 2013).

In the book Social Organizations, Charles Cooley has defined communication as a "mechanism through which human relations exist and develop -all the symbols of the mind, together with the means of conveying them through space and preserving them in time." It includes the expression of the face, attitude and gesture, the tones of the voice, words, writing, printing, railways, telegraphs, telephone, and whatever else may be the latest achievement in the conquest of space and time.

The last definition is the definition of Denis Langley and Michel Shin, which is in the dictionary of communication, 1986. They define communication as "the process of information with various communication devices from one point or one person, or from one device to another person (ibid).

In these three definitions, in addition to the evolution of the concept of communication, from the past up to present, we observe the presence of communication elements, the sender, the receiver, and the transmission of the message, as well as the effect of the message on the receiver. But paying attention to this point is essential that the world of communications has undergone many changes in its structure over the past 30 years, which has developed the nature of the communication broader than what Langley and Michel referred to. The creation of cyberspace that has offered a new kind of communication to mankind is among these structural changes. Hence, the proposed definition by Mohsenianrad, which proposes the similarity of meaning in addition to the four definitions of the communication, provides a more comprehensive concept than other definitions. This definition is as follows: "Communication is the transmission of a message from the sender to the receiver provided that the message is similar to the message or meaning of the sender of the message."

\section{Types of Communication}

Motamednejad Kazem, in the book "Mass Media" categorized communication as direct and indirect communication based on the way of the establishment of the communication and he classified communication as personal, non-personal, and mass communication based on the parties involved in the communication. Mohsenian Rad, in the communication studies, has divided communication into two types of verbal and non-verbal communication based on the use of speech in communication. Rezaian Ali, in the book "Fundamentals of Organization and Management", has divided communication into two types of unilateral and bilateral (two-way) communication in terms of how the receiver reacts to the message in the environment. Alvani Mahdi sees the basis for the classification of the communication in the structure of the organization, and he categorizes communication into two types of downward and upward communication, as well as formal and informal communication.

According to the research topic, which is the investigation of employees' informal relations, the classification of relations into two types, formal and informal relations, is closer to the topic of research than other classifications.

\section{Formal Communication}

Some communication channels are communication channels that are formally designed and implemented by managers and other stakeholders, such channels are designed to produce 
information flows in three directions of downward, horizontal and upward, and the existence of these channels is essential for connecting and coordinating the activities of people in different posts (Farhangi, 2014).

Types of formal communication patterns are as follows:

\section{1-Chain pattern}

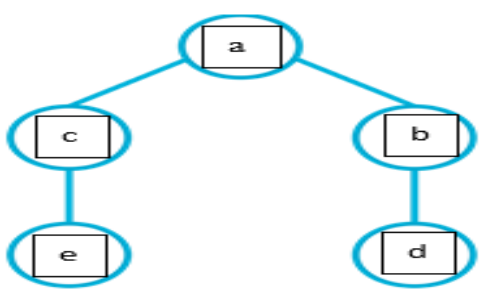

Figure 1

\section{Circle Pattern}

In the circle pattern, person (b) can only directly have contact with persons (a) and (c) and to communicate with the person (e), the communication must be established through (a) or (c) and (d) (Figure 2).

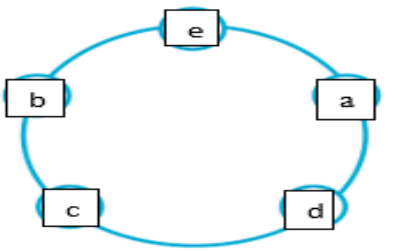

Figure 2

\section{Star Pattern (wheel)}

In the star pattern, the person (c) can directly have contact with other people, while they are not in direct contact with each other (Alvani; 2010:186). (Figure3)

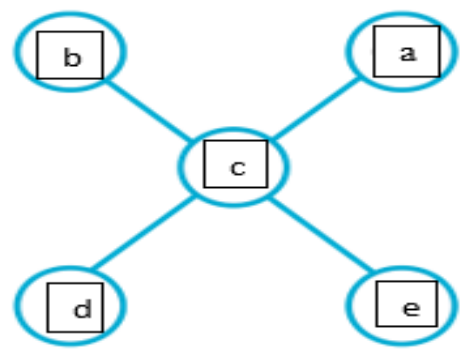

Figure 3

\section{Y Pattern}

In Y pattern, the person (C) can have contact with both (a) and (b) and with person (d), but person (e) must be established communication with persons (a) and (b) through person (d). (Figure. 4)

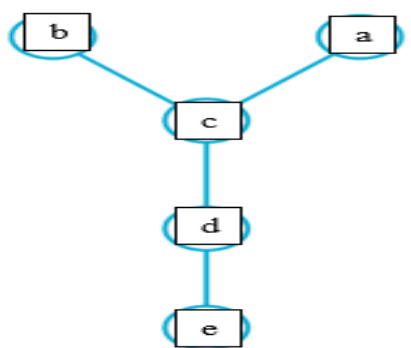

Figure 4 


\section{Informal (Grapevine) Communication}

Many organization members do not restrict their communication to only formal channels. Most people naturally tend to contact with their colleagues more than they have been assigned in formal channels. Such tendencies have led to the emergence of different types of communication channels called "informal communication channels" (Farhangi, 2014).

Sometimes, informal communication is developed so much that it eclipses official communications within an organization, and formal communication fades in informal lines (Alvani, 2010).

Types of informal communication patterns are as follows:

\section{Single- Strand Pattern}

A member of the organization informally tells a message to another person, and he transfers it to a third person and the message is then spread as a strand from one person to another (Figure 5) .

\section{Probability (Random) Pattern}

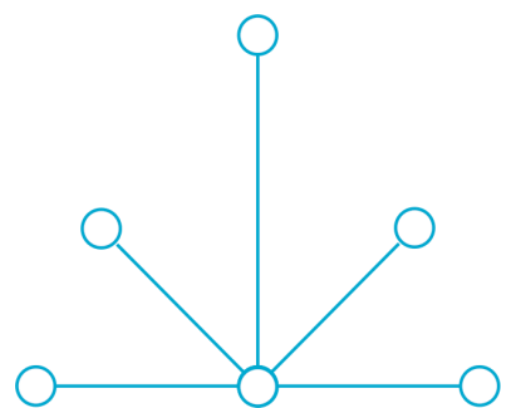

Figure 5

Probability communication is another kind of informal communication that one person randomly tells the information to others when he/she randomly has contact with others. (Figure 6)

\section{Gossip Pattern}

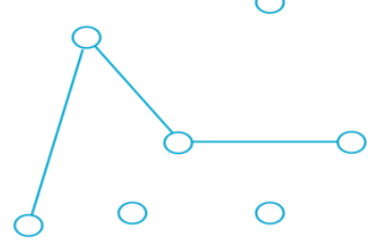

Figure 6

A person tells information to a group informally and this communication follows the gossip pattern (Figure 7).

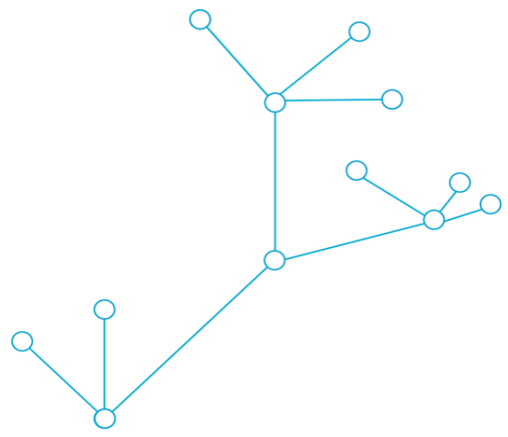

\section{Cluster Pattern}

Figure 7 
In a cluster communication, one person tells information to other persons informally and each of them passes the information to others (the same). (Figure 8)

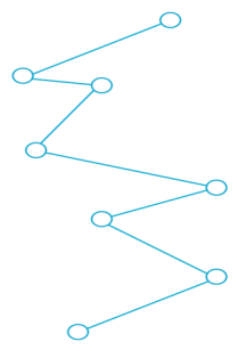

Figure 8

\section{The Importance of Informal Relations}

Mostly, the formation of activities takes place in organized and pre-planned formal systems, and hence the communication process tends to be based on planned and documented options. But informal system activities are usually spontaneous. Therefore, communications in this system are often not planned or documented. In other words, people interact directly with each other, and they want to communicate because of the nature of psychology, situational conditions and their relationships with others, and this is not due to the organization telling them to communicate (Farhangi, 2014.)

An informal informational system is a form of the organizational position that is used to meet unforeseen requirements or to compensate for unexpected situations. Of course, the ability of each organization to use informal informational systems is different. Also, the use of informal informational systems will be different depending on the conditions the organization faces (ibid).

\section{Creativity}

The humanism movement led to the literary transformations of the Renaissance period in Italy and then in other Western European countries, and its followers tried to look for metaphysics instead of heaven and solve the problems of human life relying on the human personality and human ego and his creative evolution, and attend to Socrates's statement: "know thyself (yourself) "or Protagoras's statement that "man is the measure of all things" (Qaraee Moghadam, 2008). Creativity is considered as a valuable asset and an essential for human in the twenty-first century which is used as a powerful tool for improving the quality of life (Rahmani, 2016).

\section{Definitions of Creativity}

Here the most famous definitions of creativity are presented in order to get to know more about its broad and vast spectrum:

1. Creativity means using mental abilities to create a new thought or concept.

2. Creativity is the ability to combine ideas in a unique way to establish unusual connections between different ideas.

3. Creativity is to look at the usual and common things and see their extraordinary and unusual things (Ranjbarian, 2013).

Generally, creativity is defined as the ability to present new perspectives, to generate new and meaningful ideas. Creativity is defined as the divergent thinking, the process of generating ideas from given information with an emphasis on the variety and amount of productivity. Divergent thinking includes various forms of creative thinking, the birth of ideas, divergent responses, and improving ideas. In fact, creativity is a mental activity that occurs in the absence of an accurate response from the past (Mami, Amirian, 2016). A creative organization is an organization with centralized knowledge whose nature distinguishes it. The individual's creativity is skill and talent that he/she uses to create new knowledge and implement innovations (2012; Girdauskiene, Savayeviciene). 


\section{The Importance of Creativity}

The sustainability of an organization depends on their reconstruction power; this reconstruction is done by coordinating the goals with the present status, and improving the methods to achieve these goals; for example, considers a company that wants to provide the goods and services based on the needs of customers. The needs of customers are changing over time; however, their products and services need to be provided at a good price and quality at the right time, because if the company does not accept these changes, it may lose their customers and does not desirably achieve its goals. The organization has to reinforce innovation and creativity in its adaptation to changes because non-creative organizations come to an end or are forced to improve their system over time. In fact, environmental changes and their effects on commercial and industrial units necessitate a change in them (Rezaian, 2008).

\section{Human Relations Approach}

During the late 1920s and early 1930s, a series of studies were carried out at the Western Electric Company Plant in Hawthorne City and these studies known as Hawthorne Studies led to the introduction of human relations in management (Rezaian, 2008).

Human relations are the development of practical skills to teach a person how to adapt himself to his/her social environment. The human skill is the ability to communicate with other people's beliefs and feelings so that the person's social character can be developed by receiving the desired response and the establishment of communication with others. One of the primary goals of human relations is to understand how working position is so that organizational brokers can use their potential power and work with other employees and meet individual's needs and goals in their organization (Doaee, 2011).

In terms of conceptualization, human relations means to create healthy human relationships in order to enhance the satisfaction and strengthen the morale of the people and to increase the cooperation among humans (ibid)

Human relations generally include the recognition of all behavioral interactions and social behavior of individuals in a human group. Social action and reaction is the result of all the motivations and mutual interactions among individuals in social groups and organizations. In other words, the knowledge of human relations is to examine actions and reactions that are produced among people of a society due to their association and relationships (ibid).

\section{Previous Research}

\section{Domestic Research}

Mohamed Anahid in the study of "Human Resources and Innovation Operations" examines the performance of human resources and innovation in organizations and their role in guiding individuals in the development of innovative activities. The results of the research show a positive impact of human resource performance in line with recruitment, training, participation, performance evaluation and reward for organizational innovation.

Another research entitled "The Organizational Factors Influencing the Promotion of Creativity and Innovation in the Broadcasting Organization" was carried out by Rahmanzadeh Seyed Ali. It aimed at investigating the factors influencing the promotion of creativity and innovation in the broadcasting Organization. In this research, survey and the questionnaire technique were used and the factors of the management, structure, encouragement, and incentive were effective at the creation of participation in the creativity of the employees and found a significant relationship between each of these factors and creativity.

" Analysis of the Model of Organizational, Individual, and Group Factors Influencing the Development of Innovation in Research and Technology Organizations" is another research carried out by Sadeghi Mansour et al. The purpose of the study was to identify and explain the organizational, individual and group factors influencing the development of innovation in research and technology organizations of the country in the form of presentation and testing of 
an integrated model. This research is quantitative and a descriptive research. The results of this research showed that organizational factors have the most influence on the development of innovation of such organizations and besides it, group factors including group communication, composition, cohesion, and size, and individual factors including the components of individual skill and ability, personality traits, and motivation, also affect the development of innovation in research and technology organizations.

An essay titled "Rudiments of creativity and Innovation in organizations " was done by Kalateh Amir and he examined the role of the manager in the development of the creativity and the characteristics of creative managers.

Siadat Seyed Ali et al., was conducted a research entitled "Identifying factors influencing the organizational innovation and presetting solutions for its development ". Flexibility in the face of crises, the reception of new idea from managers, flexible organizational structure, risktaking, and courage are the main features of innovative organizations. The findings also indicated that risk-taking, flexibility, creativity, self-confidence, ambiguity tolerance, creative young staff etc. are the main factors influencing organizational innovation.

\section{Foreign Research}

In 2016, Cirella et al. conducted a study entitled " Mechanisms and Creative Climate: Insights from an Italian Fashion Design company ", which investigates the relationship between different types of organizational and creative climate. The results demonstrate that cognitive, structural and procedural mechanisms are more associated with the creativity of organization than anything else.

The study of " The Creative Organization: Tomorrow's Survivor by Hitt focuses on the need for creativity for the organization and refers to the importance of examining creativity in areas other than the development unit, and the organization should be creative in different functioning areas.

"Smithian Growth through Creative Institution" is the research that was carried out by Legros et al. In this research, technology was studied as an external effect and it focused on how factories, based on labor division, could spawn the industrial revolution. Invention by observers facilitates the production process however entrepreneurs cannot internalize this benefit. Adam Smith's discourse is the theoretical basis for this study, and believes that high costs of innovations may prevent entrepreneurs from innovation.

The research "The most creative organization in the world'? The BBC, 'creativity' and managerial style was "conducted by Schlesinger in 2010. This study examines the two managerial styles of two BBC directors-general, John Birt and Greg Dyke and analyzes their different views of creativity.

\section{Methodology}

The statistical population of this study is all employees working in media companies and institutions of Tehran.

Most of the creativity researchers agree that measurement is an important aspect of creativity process. There are also stages in which they easily evaluate the creativity process and provide solutions (Basadur, 1982). For this reason, in this research, data was collected through questionnaire. The questionnaire contains seventy questions and each question containing five responses according to a Likert scale.

The order of the questions is that the first twenty questions of the questionnaire measure persons' informal relations and next fifty questions measures the level of creativity of people. Questions for examining informal relations used brain storming method and questions for creativity section are related to Rand-Sip's Creative Questionnaire. 
The Rand-Sip's Questionnaire was published in 1979 in Staff Journal. Ivancevich and Matteson in Organizational Behavior and Management in a chapter titled "Decision Making" state that Rand-Sip's Creative Questionnaire is a complete instrument for measuring creativity. Kazemi (2002) measured the reliability of the questionnaire through Cronbach's alpha using Spss software which is as follows (Zarghami et.al., 2012).

\begin{tabular}{l|l} 
Variable & Level of Cronbach's alpha \\
\hline Rand-Sip Creative & 0.73
\end{tabular}

The validity of the researcher-made questionnaire for investigating informal relations was confirmed by face validity and the confirmation of two experts in human resources and organizational communication.

The sampling method for this study is Random sampling. Comprehensive sampling is not possible in some cases and the study is limited to available population or samples (Sarokhani, 2014). For this reason, the designed questionnaire was sent to 50 persons of 5 Media Company and 36 questionnaires were returned to the researcher.

\section{Hypothesis}

"The level of creativity of people working in media companies has a direct relationship with the level of informal relations they make."

\section{Findings}

After entering the data into Spss program, demographic information was analyzed. The average age of the respondents was 26.05, including 18 men and 2 women, 16 persons did not specify their gender. Educational status of respondents was that two persons held Diploma's degree, 5 persons held Bachelor's degree, 11 persons held Master's degree, and one held Ph.D. degree. Also, 17 persons did not mention their degree.

Then to investigate the relationship between two variables of informal relations and creativity, two variables of informal relations (OnOfficial) and creativity (Creative) were defined. Then, the relationship between these two variables was investigated using linear regression so that informal relations were considered as independent variable and creativity as the dependent variable. In the following section, we analyze the findings of linear regression analysis in Spss software.

As it is shown in Table 1, the variance level that the dependent variable of Creativity is justified by the informal relations is a very low number.

Table 1

\begin{tabular}{|l|l|l|l|l|}
\hline Model & $\mathrm{R}$ & $\begin{array}{l}\mathrm{R} \\
\text { Square }\end{array}$ & $\begin{array}{l}\text { Adjusted R } \\
\text { Square }\end{array}$ & $\begin{array}{l}\text { Std. Error } \\
\text { of the } \\
\text { Estimate }\end{array}$ \\
\hline 1 & $.059^{\mathrm{a}}$ & .003 & -.026 & .18127 \\
\hline a. Predictors: (Constant), OnOfficial & & \\
\hline
\end{tabular}

According to Table 2 level of $\mathrm{F}$ is 0.117 and its sig is 0.735 . Therefore, the significance of regression model with two variables is very low.

Table 2

\begin{tabular}{|c|c|c|c|c|c|c|}
\hline \multicolumn{7}{|c|}{ ANOVA $^{a}$} \\
\hline \multicolumn{2}{|c|}{ Model } & $\begin{array}{l}\text { Sum of } \\
\text { Squares }\end{array}$ & df & $\begin{array}{l}\text { Mean } \\
\text { Square }\end{array}$ & $\mathrm{F}$ & Sig. \\
\hline \multirow[t]{3}{*}{1} & Regression & .004 & 1 & .004 & .117 & $.735^{b}$ \\
\hline & Residual & 1.117 & 34 & .033 & & \\
\hline & Total & 1.121 & 35 & & & \\
\hline \multicolumn{7}{|c|}{ a. Dependent Variable: Creative } \\
\hline \multicolumn{7}{|c|}{ b. Predictors: (Constant), OnOfficial } \\
\hline
\end{tabular}


Table 3 shows the significant relationship between the two variables of informal relations and creativity through t-test. As it can be seen, the sig. for this test is 0.735 and the relationship between these two variables is not significant.

Table 3

\begin{tabular}{|c|c|c|c|c|c|c|}
\hline \multicolumn{7}{|c|}{ Coefficients $^{a}$} \\
\hline \multirow{2}{*}{\multicolumn{2}{|c|}{ Model }} & \multicolumn{2}{|c|}{ Unstandardized Coefficients } & \multirow{2}{*}{$\begin{array}{c}\text { Standardized } \\
\text { Coefficients } \\
\text { Beta }\end{array}$} & \multirow[t]{2}{*}{$\mathrm{t}$} & \multirow{2}{*}{ Sig. } \\
\hline & & B & Std. Error & & & \\
\hline \multirow[t]{2}{*}{1} & (Constant) & .067 & .064 & & 1.048 & .302 \\
\hline & OnOfficial & .027 & .080 & .059 & .342 & .735 \\
\hline
\end{tabular}

\section{Discussion and Conclusion}

Organizations need new thoughts and ideas in order to survive and sustain their positive and constructive role so that they can guarantee their dynamism by adopting new perspectives based on field research, ideas and theories, otherwise, they will have the breakdown (Abdollahi, 2008). This research, by examining the relationship between informal relations and creativity, sought to examine informal relations as a way to increase the creativity of employees in organizations. By analyzing the data gathered from the questionnaires, there was no significant relationship between these two variables. Unlike previous research, this research considered creativity as a separate variable from innovation, it also distinguishes informal relations from communication factor, and this leads to a closer look at the issue of creativity in the organization. A topic is suggested for other researchers and the reason for the lack of relationship between two variables of informal relations and creativity can be clarified. For this purpose, researchers can examine the impact of informal relations on motivation, because the research carried out reflects the positive impact of motivation on creativity.

\section{References}

A. Hitt, Michael. The Creative Organization: Tomorrow's Survivor. Organizational need for creativity.

Abdollahi, Abutaleb: (2008). The Role of Managers and Organizations in Creativity and Innovation. Hason Journal. Number 16.

Alvani, Seyed Mehdi: (2010). General Management. Ney Publication. Thirty-Ninth Edition.

Anahid, Mohammad: (2013). Human Resources and Innovation Operations in the Organization. Human Sciences Research. Vol. 5, No. 30

Basadur, Min:(1982). Training in creative problem solving: effects on ideation and problem finding and solving in an industrial research organization.

Cirella, Stefano; Canterino, Filomena; Guerci, Marco; B. (Rami) Shani, Abraham:(2016). Organizational Learning Mechanisms and Creative Climate: Insights from an Italian Fashion Design Company

David, Fred R: (2016). Strategic Management. Translator: Parsaian Ali. Arabi Seyyed Mohammad. Cultural Studies. Thirty Fourth Edition.

Doaee, Habibollah: (2011). Theories and processes of organizational communication. First Edition.

Farhangi, Ali Akbar: (2014). The Theories of Organizational Communications. Rasa Institute for Cultural Service. Fifth Edition.

Girdauskiene, Savaneviciene; Lina, Asta:(2012). Leadership role implementing knowledge transfer in creative organization: how does it work? International Conference on Leadership, Technology and Innovation Management

Kalateh, Amir: (2009): Rudiments of creativity and Innovation in organizations. The Insight and Islamic Education Quarterly. Sixth Year. Numbers 13. 
Legros, Patrick; Newman, Andrew F; Proto, Eugenio. SMITHIAN GROWTH THROUGH CREATIVE ORGANIZATION

Mami, Shahram; Amirian, Kamran: (2016). The Effect of Creative Drama on Students' Social Adjustment, Moral Judgment and Creativity. The Journal of Instruction and Evaluation.

Mohsenian Rad, Mehdi: (2013). Communication Studies. Soroush Press. Fourteenth Edition.

Motamed Nezhad, Kazem: (2012). The Mass Communication. Allamah Tabatabai University Publications. Ninth Edition.

Qaraee Moghadam, Amanollah: (2008). Creativity and Innovation in Organization Management. Work and Society Journal: No. 94 and 95

Rahmani, Soodeh; Kadivar Parvin; Sarami; Gholamreza; Hejazi; Elaheh: (2016). Creativity prediction based on the individual and contextual variables of the Sternberg Investment Theory. Psychological Quarterly.

Rahmanzadeh, Seyed Ali (2016). The Organizational Factors Influencing the Promotion of Creativity and Innovation in the Broadcasting Organization. Educational science. Innovation and creativity in the human scientice. Winter 2016. issue6. Number 3

Ranjbarian, Rasool: (2013). Creativity and Innovation in Organizations. Work and Society Monthly Social, Economic, Scientific, and Cultural Magazine, No. 161, September 2013.

Rezaian, Ali: (2008). Fundamentals of Organization and Management. Publications. Samt Publication. Twelfth Edition.

Sadeghi, Mansour; Sadeghi, Ali Reza; Niko Kar, Gholam Hossein; Naderi Khorshidi, Ali Reza: (2011). Analysis of the Model of Organizational, Individual, and Group Factors Influencing the Development of Innovation in Research and Technology Organizations. The second half of 2011. Number 5.

Saroukhani, Baqer: (2014). Research method in social sciences. Second volume. Publications of the Institute of Humanities and Cultural Studies. Tenth Edition.

Schlesinger, Philip:(2010). The most creative organization in the world'? The BBC, 'creativity' and managerial style. International Journal of Cultural Policy Vol. 16, No. 3.

Siadat Ali, Chopani, Haidar, Kazempour, Maryam, Maleki Hassanvand, Moslem: (2013) Identifying factors influencing the organizational innovation and presetting solutions for its development. Innovation and Creativity in the human science. Issue 3. Number 1.

Wimier; Dominique; Roger Di, Joseph R; Seyed Emami, Kawosh: (2014). Research in Mass Media. Soroush Press. Fourth Edition.

Zarghami, Hamid Reza, Jafari, Mostafa, Akhavan, Peyman: (2012). The Study of the Relationship between Creativity and the Motivation for Innovation in Research Organizations: Case Study: Research Center of Intelligent Signal Processing. Innovation and Creativity in Human Science Journal. Spring 2012. Number 4. 